\title{
EUTOMIA
}

Revista de Literatura e Linguística

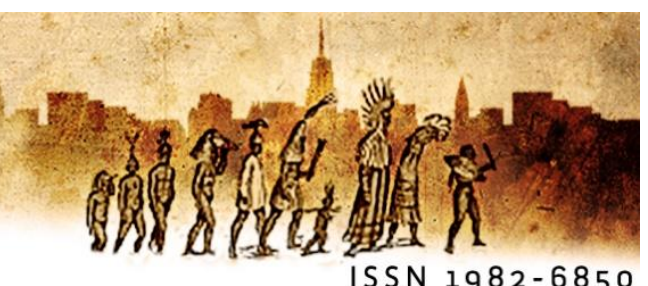

ISSN $1982-6850$

\section{À busca de um ensino renovado de gramática: convivendo com embate de identidades do professor de Língua Portuguesa no ensino de gramática}

\author{
Ana Maria de Mattos Guimarães' (UNISINOS/CNPq)
}

Fernanda Machado Bartikoskii (UNISINOS/CAPES)

\section{Resumo:}

A homologação da Base Nacional Comum Curricular (BNCC) (BRASIL, 2017) trouxe novamente à tona questões do que denomina de eixo da análise linguística/semiótica. É nesse contexto que este artigo busca refletir sobre questões teóricas e didáticas a ele relacionadas, na tentativa de também trazer à discussão a retomada do termo gramática, entendido aqui como plural. As considerações, a seguir apresentadas, fazem parte de projeto de formação continuada de professores de Língua Portuguesa, no qual foram desenvolvidas duas proposições de transposição didática de objetos de ensino de gramática na procura de um ensino renovado de gramática: uma voltada para a interação entre texto e gramática, outra destinada ao estudo de tópicos linguístico-textuais transversais à escrita de qualquer texto. $O$ desenvolvimento do trabalho junto aos professores permitiu verificar o embate de identidades por que eles passam, ao serem defrontados com uma proposta de ensino renovado. Nesse cenário, analisa-se o trabalho de uma docente ao propor atividades sobre elementos linguísticos significativos para a produção de textos de um determinado gênero.

Palavras-chave: gramática; análise linguística; ensino de gramática; projeto didático de gênero.

\begin{abstract}
:
The homologation of the Common National Curricular Standards (BNCC) (BRAZIL, 2017) has brought up again issues it designates as the axis of linguistic/semiotic analysis. It is in this context that this paper aims to reflect upon the theoretical and pedagogical issues attached to this very axis, in an attempt to also discuss the use of the word grammar, understood here as a multifaceted term. The considerations presented below are part of a continuing education program for Portuguese teachers, in which two propositions of didactic transposition of grammar teaching objects have been developed in search of a new way to teach grammar: one oriented to the interaction between text and grammar and the other
\end{abstract}


focused on the study of linguistic-textual topics that crosscut the writing of any text. The work developed with the teachers allowed us to verify the identity clash these professionals go through when faced with a new form of teaching. Within this scenario, this paper analyzes the work of one teacher as she presents activities on linguistic elements that are meaningful to the production of texts from specific genres.

Keywords: grammar; linguistic analysis; grammar teaching; didactic project of genre.

\section{Introduzindo o tema}

Este artigo nasceu de inquietações de nosso grupo de pesquisa sobre a forma como o ensino (ou não) da gramática vem sendo tratado na realidade da sala de aula. Renominado de análise linguística/semiótica pela Base Nacional Comum Curricular (BNCC) (BRASIL, 2017) o uso de elementos gramaticais é visto, no documento, sobretudo pelos efeitos de sentido que podem ocasionar. Compreendemos a importância de acentuar essa questão, mas o ensino de gramática pode ser visto apenas por esse ângulo? Não é possível pensar num ensino de gramática de forma plural ${ }^{1}$, a partir de uma concepção de linguagem voltada para a interação, em que o estudo da linguagem se dá em situações de uso da língua, uma vez que é na interação que o sujeito age e se relaciona com o outro e com o mundo?

Por outro lado, é preciso considerar que, embora se fale em ensino renovado de gramática desde a década de 8o (cf. GERALDI, 2006), ao adentrarmos a realidade da sala de aula de língua portuguesa (cf., por exemplo, GUIMARÃES, 2006; 2010), encontramos, muitas vezes, um ensino de gramática bastante mecânico, desarticulado do uso nas diferentes práticas de linguagem, com frequência, como equivalente à extração de elementos do texto. Parece haver uma repetição de conteúdos gramaticais ao longo da escolaridade, com predomínio da função metalinguística, ou melhor, da nomenclatura gramatical, e da descontextualização dos elementos gramaticais ensinados. A concepção de linguagem na base dessa perspectiva continua sendo a de entendê-la como norma, como homogênea, desvinculada das diferentes práticas que a concretizam. O processo de mudança de uma concepção para a outra, que parece estar claro dentre os estudiosos da área (ANTUNES, 2014; 2007; 2003; GERALDI, 2006; MENDONÇA, 2006, entre outros),

\footnotetext{
${ }^{1}$ Estamos preferindo utilizar o termo ensino de gramática, e não de análise linguística, por entendermos que o primeiro contempla uma visão plural do objeto de ensino, que vai desde o trabalho com a gramática em interação com o gênero até a exploração de determinados tópicos linguístico-textuais.
} 
ainda está obscuro para grande parte dos docentes e continua a desafiar aqueles que se propõem a pensar sobre como transpor didaticamente essas diferenças, no que se refere ao ensino de gramática. É nesse sentido que passaremos a refletir sobre o ensino da gramática, a partir do processo de formação continuada ${ }^{2}$ que vimos desenvolvendo junto a um município do sul do país.

\section{Contextualizando o cenário}

A pesquisa em curso permitiu-nos desenvolver uma formação continuada em ciclos, como descritos a seguir (cf. GUIMARÃES; CARNIN, 2019):

- Ciclo 1: Sensibilização para a participação efetiva na formação e para os conceitos considerados estruturantes/reguladores das práticas. Este foi um ciclo voltado para o conjunto dos cursistas (professores de $5^{\circ}$ ano, de Língua Portuguesa dos anos finais e coordenadores pedagógicos), sempre preocupado com atividades dinâmicas, que fizessem os professores saírem do lugar de espectadores.

- Ciclo 2: Discussão da Base Nacional Comum Curricular (BNCC) (BRASIL, 2017) e sua proposta de ensino de língua materna, através dos quatro eixos nela propostos: oralidade, leitura, produção escrita e análise linguística, trabalhados em diferentes oficinas.

- Ciclo 3: Síntese globalizadora: revisão dos conceitos-base que nortearam todas as oficinas e exploração do dispositivo didático dos projetos didáticos de gênero (PDG), como uma forma de trabalhar os diferentes eixos em conjunto ${ }^{3}$.

- Ciclo 4: Vivência comunitária entre os professores cursistas e os mentores, formado pelo grupo de pesquisa que preparou o curso, para elaboração de PDG adequado às turmas em que os docentes lecionam língua portuguesa.

- Ciclo 5: Retorno à práxis para discussão com os alunos do planejamento dos PDG (escolha do tema e do(s) gênero(s) de texto), seguida de volta à vivência comunitária com os mentores para (re)construção do planejamento do PDG, incluindo o modelo

\footnotetext{
2 Tais reflexões foram motivadas pelo projeto de pesquisa "Formação continuada e comunidades de desenvolvimento profissional: aproximações teórico-práticas", apoiado pelo CNPq, através do Edital $\mathrm{MCTI} / \mathrm{CNPO} \mathrm{N}^{\circ}$ 01/2016 - Universal, e coordenado pela primeira autora deste artigo. A pesquisa da segunda autora tem também apoio CAPES.

3 Não propusemos esse dispositivo como a única estratégia a ser utilizada, enfatizamos também a necessidade de desenvolver atividades mais específicas de um determinado eixo, como seria, por exemplo, o caso de um tópico linguístico-textual que atravesse diferentes gêneros de textos.
} 
didático do gênero a ser trabalhado e a preocupação com atividades que possam também abarcar leitura e/ou análise linguística, e/ou oralidade.

- Ciclo 6: Apresentação pelos professores dos PDG desenvolvidos, em aula aberta para a comunidade universitária e com convidados-debatedores, pesquisadores externos à formação.

- Ciclo 7: Vivência de comunidades de desenvolvimento com apoio da Secretaria Municipal de Educação do município parceiro e mentoria do grupo de pesquisa de forma presencial ou a distância. Desenvolvimento não só de PDG, mas também de projetos mais focados em análise linguística ou em oralidade.

- Ciclo 8: Maior envolvimento dos professores que participaram da formação e das comunidades de desenvolvimento profissional, agora também como mentores de outros professores que se agregarão a essas comunidades. Os próprios professores da rede com mais experiência nas práticas vivenciadas passam a mentorar os novos professores que chegam às comunidades, numa formação que se aproxima das comunidades de prática e de seus traços definidores, como os elencados por Holmes e Meyerhoff (1999). Os membros do grupo de pesquisa, antes mentores, permanecessem ligados a essas comunidades, como apoio para resolução de dúvidas e para tomada de decisões.

O projeto está ainda em desenvolvimento, tendo atingido seu oitavo ciclo. A formação em ciclos permitiu-nos relacionar mais concretamente as propostas que trazíamos de um ensino renovado com as vivências dos professores e acompanhar seu desenvolvimento. Para fins deste artigo, destacamos o trabalho realizado no segundo ciclo com o eixo de análise linguística ${ }^{4}$ e trazemos exemplos da professora Luciana (nome fictício), uma das participantes da formação, procurando mostrar as modificações ocorridas durante as suas vivências nos diferentes ciclos.

A oficina sobre análise linguística foi desenvolvida em dois encontros presenciais. $O$ primeiro esteve focado na conceituação de análise linguística e em como tal conceito é abordado na BNCC. Já o segundo encontro foi direcionado para o estudo da análise linguística em interação com os gêneros textuais. Para isso, os professores, com o auxílio

\footnotetext{
${ }^{4}$ Embora defendamos o termo ensino de gramática, optamos pelo título Oficina sobre análise linguística para estarmos mais coerentes com o objetivo geral do Ciclo 2, que era o de trabalhar com os eixos integradores presentes na BNCC (BRASIL, 2017) de Língua Portuguesa. Da mesma forma, o emprego de análise linguística se estende às práticas desenvolvidas dentro dos ciclos da formação continuada que propusemos.
} 
das formadoras, realizaram a análise de exemplares do gênero panfleto, a fim de mapear elementos linguísticos significativos para a escrita desse gênero. Em seguida, os próprios docentes realizaram atividades de análise linguística, no papel de alunos.

No Quadro 1, podemos visualizar um resumo das atividades propostas nos dois encontros de formação, além dos objetivos traçados para cada uma delas.

\section{Quadro 1 - Resumo da Oficina sobre Análise Linguística}

\begin{tabular}{|c|c|}
\hline Atividades & Objetivos \\
\hline \multicolumn{2}{|c|}{ Primeiro encontro } \\
\hline $\begin{array}{l}\text { 1) Apresentação de uma atividade de gramática } \\
\text { desenvolvida em sala de aula: } \\
\text { - Professores: minha(s) proposta(s) para o } \\
\text { ensino de gramática. } \\
\text { - Coordenadores: um exemplo de atividade que } \\
\text { julga ser frequente na sua escola. }\end{array}$ & $\begin{array}{l}\text { - Conhecer os tipos de atividades que circulam } \\
\text { nas aulas de Língua Portuguesa; } \\
\text { - Compreender quais são as concepções de } \\
\text { linguagem adotadas pelos professores. }\end{array}$ \\
\hline $\begin{array}{l}\text { 2) Discussão do conceito de análise } \\
\text { linguística/semiótica presente na BNCC } \\
\text { (BRASIL, 2017), a partir da seguinte pergunta: } \\
\text { De que forma o eixo da análise } \\
\text { linguística/semiótica pode se materializar em } \\
\text { nossas práticas em sala de aula? }\end{array}$ & $\begin{array}{l}\text { - Articular os pressupostos presentes na BNCC } \\
\text { com a prática dos professores em suas salas de } \\
\text { aula. }\end{array}$ \\
\hline $\begin{array}{l}\text { 3) Dinâmica em grupos para a construção de } \\
\text { uma tabela comparativa: ensino tradicional de } \\
\text { gramática } x \text { análise linguística. }\end{array}$ & $\begin{array}{l}\text { - Construir uma compreensão conjunta a } \\
\text { respeito das diferenças presentes no ensino } \\
\text { tradicional de gramática e na prática de análise } \\
\text { linguística. }\end{array}$ \\
\hline $\begin{array}{l}\text { 4) Apresentação dos diferentes tipos de } \\
\text { atividades e suas principais características } \\
\text { (atividades linguística, epilinguística e } \\
\text { metalinguística), de acordo com Franchi (1988). }\end{array}$ & $\begin{array}{l}\text { - Abordar os tipos de atividades com base nos } \\
\text { objetivos presentes em cada um deles; } \\
\text { - Discutir, a partir de exemplos dos livros } \\
\text { didáticos, os objetivos que subjazem a cada } \\
\text { tipo de atividade. }\end{array}$ \\
\hline $\begin{array}{l}\text { 5) Análise das atividades de gramática trazidas } \\
\text { pelos professores e coordenadores à luz dos } \\
\text { tipos de atividades. }\end{array}$ & $\begin{array}{l}\text { - Propor uma reflexão sobre as atividades que } \\
\text { os docentes fazem em sala de aula, seus } \\
\text { objetivos e sua relação (ou não) com a análise } \\
\text { linguística; } \\
\text { - Diferenciar os objetivos de propostas de } \\
\text { ensino voltadas para a (1) análise linguística em } \\
\text { interação com os gêneros textuais e (2) para o } \\
\text { ensino focado em tópicos linguísticos- } \\
\text { gramaticais. }\end{array}$ \\
\hline
\end{tabular}




\section{Segundo encontro}

6) Relação entre o ensino de gêneros textuais e - Discutir como se dá a prática de análise as abordagens para o ensino de língua (ensino linguística com base nos gêneros textuais.

tradicional de gramática e análise linguística).

7) Análise linguística no projeto didático de gênero (PDG).

- Mapear quais elementos linguísticos eram significativos para a escrita do gênero panfleto; - Propor uma atividade de análise linguística.

8) Atividades de análise linguística: os professores no papel de alunos.

- Expor os docentes a uma experiência didática, em que eles estivessem no papel de alunos, a fim de que pudessem experienciar atividades de análise linguística;

- Discutir a experiência.

9) Dinâmica de encerramento: $O$ que levo desta - Conhecer quais foram as aprendizagens mais oficina de análise linguística? e $O$ que eu ainda quero aprender sobre o assunto? significativas dos docentes ao longo da oficina; - Saber quais foram as limitações da oficina, para alterá-la/repensá-la para as próximas formações.

Fonte: BARTIKOSKI; MATIAS, no prelo.

Durante a oficina, foi possível perceber que a grande inquietação dos professoresparticipantes estava no como fazer, isto é, em como transpor os conhecimentos teóricos sobre análise linguística para a realidade da sala de aula, no planejamento de projetos e/ou atividades de Língua Portuguesa que fizessem sentido para os alunos e que, sobretudo, estivessem ligadas a práticas renovadas de ensino de língua. Duas professoras foram acompanhadas por uma mentora durante o Ciclo 4, momento em que os docentes estavam planejando seus PDG, com o intuito de desenvolver oficinas, dentro do projeto didático, voltadas para a análise linguística.

\section{Revisando o tema}

Não é novidade a preocupação com o ensino da gramática e a necessidade de sua renovação (GERALDI, 2006; POSSENTI, 1996; ANTUNES, 2003, 2007 e 2014; NEVES, 1991; CAMPS, 2006; BULEA-BRONCKART, 2016). O ensino tradicional, ainda muito presente, baseia-se numa concepção de língua como sistema uniforme, no qual não ocorre variação, muito ligada aos preceitos da gramática normativa. As regras são apresentadas a priori, sem que sejam levadas em consideração as diferentes práticas de linguagem. Tentando descrever uma língua homogênea, o ensino tradicional de gramática recorre à norma- 
padrão, prescrevendo normas e regras de uso da língua que, muitas vezes, não são mais usadas, inclusive pelos falantes mais cultos (FARACO, 2008). Por estar muito focada no estudo sobre a língua, essa visão de ensino de gramática privilegia atividades que visam à denominação e à classificação dos fatos da língua.

Em consequência disso, ocorre também a falta de diálogo entre a gramática e os demais eixos de ensino. O aluno acaba estudando a gramática como se esta fosse um eixo à parte, sem nenhuma interlocução com a leitura, a escrita e a oralidade. Muitas vezes, o texto serve de pretexto para a prática extrativista, na qual são retiradas palavras e frases que servem de exemplo para determinado conteúdo.

O movimento de ruptura com as práticas de ensino centradas na gramática tradicional se intensificou a partir do momento em que o texto passou a ser entendido como a unidade de trabalho privilegiada para o ensino da Língua Portuguesa, sobretudo a partir da homologação dos documentos oficiais: os Parâmetros Curriculares Nacionais (PCN) (BRASIL, 1998) e, mais recentemente, a BNCC (BRASIL, 2017). A posição de destaque assumida pelo texto evidencia a opção por um ensino de língua preocupado em assegurar o desenvolvimento das capacidades de linguagem dos alunos, e não apenas o domínio da metalinguagem. Nesse sentido, a concepção de linguagem como interação, assumida pelos documentos oficiais, se apresenta como determinante para a definição dos objetos ensino e como estes devem ser transpostos para as aulas.

Sob essa nova concepção, o paradigma da aula de Português muda, uma vez que é posta em xeque a ideia de que ensinar língua significa ensinar gramática (ANTUNES, 2003). Pensar em objetos de ensino de gramática, a partir da interação, requer um novo olhar do professor com relação às práticas de linguagem e, sobretudo, às produções textuais de seus alunos, como já preconizava Geraldi (2006). Isto é, a definição do que ensinar não é mais determinada pelos conteúdos gramaticais, muitas vezes delimitados com base na gramática normativa, mas sim pelas diversas práticas de linguagem e pelas necessidades dos alunos, evidenciadas em seus textos.

Neste percurso, um mesmo professor pode tanto desenvolver práticas tradicionais quanto práticas inovadoras de ensino em suas aulas, uma vez que essas podem coexistir. Como dissemos em artigo recente (GUIMARÃES, 2016), o professor vive um embate entre identidades, principalmente entre a de professor inovador - aquele que delineamos durante 
a formação - e o professor tradicional. ${ }^{5} \mathrm{~A}$ tentativa de aliar uma nova perspectiva a formas conhecidas de ensinar é natural num processo de apropriação de uma proposta teóricometodológica diferente da sua prática cotidiana. Isso se explica porque não é possível, para o professor, desvencilhar-se do que crê ser sua própria identidade profissional, de uma hora para outra, pois repensar a sua prática também envolve uma mudança em sua forma de compreender a linguagem. Nesse sentido, atravessa-se um momento especial, em que convivem velhas e novas práticas no espaço da aula de Língua Portuguesa (aqui pensando mais em sua aula de gramática), por vezes, conflituosas. (MENDONÇA, 2006).

Para pensar um ensino renovado de gramática, o ponto de partida do trabalho foi semelhante ao que pensamos para a didatização de gênero, a resposta à pergunta: "Por que estamos ensinando o que estamos ensinando neste momento para estes alunos?" Ampliamos o foco do ensino para incluir a reflexão e o uso da língua, como afirma Faraco (2006, p. 25): "Refletir sobre a estrutura da língua e sobre seu funcionamento social é atividade auxiliar indispensável para o domínio da fala e da escrita".

Para isso, entendemos que não existe uma única receita, mas diferentes práticas/atividades que permitam a exploração de diferentes objetos gramaticais em um ensino plural. Em suma, o ensino de gramática que propomos está assentado na análise e reflexão do funcionamento da língua que se desdobra em (1) importância de atividades linguísticas e epilinguísticas para o ensino do objeto gramatical; (2) ensino da metalinguagem, no sentido de sistematização do objeto de ensino, e (3) escolha de um objeto de ensino gramatical que responda às necessidades demonstradas pelos aprendizes.

Os diferentes tipos de atividades que podem acompanhar o ensino gramaticallinguísticas, epilinguísticas e metalinguísticas (FRANCHI, 1988) - e seus objetivos e funções são alicerces para o que pretendemos construir.

A atividade linguística é entendida como o pleno exercício da linguagem, pois propicia o contato com a língua em uso, por meio da escrita, da leitura e da oralidade. Por intermédio desta primeira atividade, o aluno já é capaz de se aprofundar nos estudos linguísticos, estando apto para realizar atividades epilinguísticas, que consistem na análise

\footnotetext{
${ }^{5}$ Estamos entendendo identidade como uma construção social, definida pelo sentimento de pertencer a um determinado grupo, salientando-se que cada um de nós vive uma variedade de identidades potencialmente contraditórias (Weeks,1990, p. 88). No caso da formação continuada, pode-se pensar justamente na (con)vivência/embate de duas identidades: a do professor tradicional $\mathrm{x}$ a do professor inovador, pois os docentes da pesquisa convivem profissionalmente com grupos diferentes.
} 
dos efeitos de sentido, comparação de expressões, manipulações/experimentações de tópicos para depreensão de regularidades, entre outras ações que permitam ao aprendiz a construção de conhecimento sobre dado objeto gramatical. Por fim, a atividade metalinguística está voltada para a sistematização da língua e sua descrição, dando conta do caráter sistêmico de sua organização e abrangendo também o uso de nomenclaturas, não como foco, mas como consequência do estudo. Cabe ao professor pensar se é necessário ou não, a partir da sua proposta de ensino, apresentar a nomenclatura a seus alunos. Franchi (1988) defende que, antes de dominar conhecimentos metalinguísticos, os alunos deveriam refletir sobre a própria linguagem.

Dessa forma, na negociação de sentidos que estabelecemos com os professores em formação, priorizamos:

- Importância do conceito de gramática a partir do entendimento de linguagem como interação: a atividade linguística propicia o contato com a linguagem em uso, por meio da escrita, da leitura e da oralidade.

- Entendimento de que o ensino de gramática/análise linguística leva à reflexão sobre a língua, num processo que envolve atividades linguísticas, epilinguísticas e metalinguísticas.

- Utilização de produções textuais dos próprios alunos ou produções contemporâneas para manipulação dos fatos gramaticais: operar sobre a linguagem, analisar os efeitos de sentido, comparar expressões, entre outras ações, para, posteriormente, como consequência do estudo sobre a língua, voltar-se para a sistematização da língua e sua descrição, incluindo o uso de nomenclaturas.

Para dar conta desses princípios, propomos duas formas de transposição didática do objeto gramatical:

- Tratando-se de elementos linguísticos significativos para a composição do gênero, seu estudo deve articular-se à produção de textos de um determinado gênero, no nosso caso, como parte integrante dos projetos didáticos de gênero, e ser orientado pelas dificuldades reveladas pelos alunos em suas produções iniciais;

- Tratando-se de tópicos linguístico-textuais que perpassam diferentes gêneros (como concordância, pontuação, mas também, conectores, modalizadores, complementos e adjuntos nominais e verbais, etc.), seu estudo merece projeto 
específico, sempre pensado a partir das capacidades linguísticas dos alunos e da progressão de suas aprendizagens.

A opção pelo ensino de determinado tópico viria das necessidades apresentadas pelos próprios alunos, evidenciadas, por sua vez, pelas suas produções textuais, partindo das suas capacidades linguísticas para a progressão de suas aprendizagens. Para isso, poderíamos pensar em etapas: (i) análise de textos produzidos pelos alunos, como forma de verificar qual(is) tópico(s) (ainda) não teve(tiveram) sua aprendizagem consolidada ou, até mesmo, não é(são) contemplado(os) nos textos; (ii) produção de uma descrição do tópico selecionado, para que se possa abranger seus diferentes usos, tendo como base: (a) gramáticas com perspectivas diferentes, como, por exemplo, a gramática normativa, a gramática descritiva e a gramática pedagógica; (b) obras de referência da área da Linguística; (c) textos pertencentes a diferentes gêneros de texto, para a observação dos usos e das regularidades do tópico em estudo; (iii) visando à transposição didática: produção de um projeto de ensino voltado para o tópico linguístico-textual a ser ensinado; (iv) pilotagem da proposta de ensino, a partir de atividades linguísticas e epilinguísticas, para, após, chegar a atividades metalinguísticas (utilizando a nomenclatura, quando entendê-la necessária para aquele grupo de alunos); e (v) avaliação ao longo do desenvolvimento da proposta, como também após o seu término, por meio de produções de textos, no sentido de compreender a transposição dos conhecimentos apreendidos para outros contextos de escrita. Nesse percurso, é necessário que haja uma forte relação entre pesquisadores e professores (de acordo com o que delineamos para nossas comunidades de desenvolvimento profissional), tendo em vista a complexidade da construção de modelo didático de gramática.

Pensando na interação entre texto e gramática, o ponto de partida é o gênero de texto a ser trabalhado, a partir do qual são enfatizados um ou dois elementos linguísticos significativos para a escrita do gênero em questão e que, nas produções iniciais dos alunos, apresentam algum problema. As etapas dessa proposta podem ser assim definidas: (i) seleção, no Modelo Didático do gênero que será estudado, de elementos linguísticos significativos para a produção de textos; (ii) diagnóstico desses elementos a partir da produção inicial do gênero; (iii) planejamento de oficinas tendo tais elementos como objetos de ensino dentro do projeto didático do gênero, baseando-se, principalmente, em atividades linguísticas e epilinguísticas; (iv) comparação entre a produção final do gênero e 
a produção inicial, como forma de analisar o sucesso (ou insucesso) do ensino desses elementos.

Para a concretização das propostas que apresentamos, é necessário entender melhor como o professor está (ou não) internalizando as propostas da formação, como sua identidade é alterada durante o processo, o que pode ser verificado no acompanhamento à professora de $5^{\circ}$. ano, Luciana (nome fictício), formada em Pedagogia e há 3 anos na docência.

\section{Dando pequenos passos: entre o tradicional e o renovado}

\subsection{A professora antes da formação}

O primeiro momento da observação das aulas da professora Luciana ocorreu antes da formação de que ela viria a participar, no momento em que apresentou aos alunos o que considerava um conteúdo novo de Língua Portuguesa para eles, os pronomes. O ponto de partida da aula foi a retomada oral de duas classes gramaticais já estudadas naquele ano: o substantivo e o adjetivo. A turma se mostrou um pouco confusa, alguns até disseram que não lembravam mais o que eram substantivos e adjetivos. A professora, para ajudá-los, lembrou que o substantivo é a classe de palavras que nomeia os seres e o adjetivo é a classe que atribui uma qualidade. Além disso, alertou que seria importante todos relembrarem o que eram essas duas classes, já que, naquela aula, eles aprenderiam outra, a classe dos pronomes.

No quadro, Luciana escreveu uma explicação geral do que seriam os pronomes, incluindo sua função e suas subdivisões.

\section{Quadro 2 - Reprodução do quadro-negro (Parte 1)}

\section{Pronomes}

Pronomes são palavras que substituem ou acompanham os nomes dos seres, objetos, sentimentos e fenômenos.

Os pronomes podem nos situar quanto à pessoa gramatical do discurso, ou seja, indicar quem fala $\left(1^{\mathrm{a}}\right.$ pessoa), com quem se fala ( $2^{\mathrm{a}}$ pessoa) e de quem se fala ( $3^{\mathrm{a}}$ pessoa, tanto no singular quando no plural).

Os pronomes podem ser pessoais, que são subdivididos em retos, oblíquos e de tratamento. Temos também os pronomes possessivos, pronomes indefinidos e pronomes demonstrativos.

Pronome pessoal reto - exerce função de sujeito. 
Exemplo: Eles caminham no deserto por anos.

$\begin{array}{ll} & \text { Pronomes pessoais retos } \\ \text { Singular } & 1^{\text {a }} \text { pessoa - eu } \\ & 2^{\text {a }} \text { pessoa - tu } \\ & 3^{\text {a }} \text { pessoa - ele/ela } \\ \text { Plural } & 1^{\text {a }} \text { pessoa - nós } \\ & 2^{\text {a }} \text { pessoa - vós } \\ & 3^{\text {a }} \text { pessoa - eles/elas }\end{array}$

Após a cópia, a professora começou sua explicação, quando repetiu que os pronomes retos exercem sempre a função de sujeito, e apresentou o quadro dos pronomes, no qual constava vós. Nenhum aluno, entretanto, fez alguma pergunta referente à função sintática, ou à possibilidade do uso dos pronomes retos em função de objeto (Eu vi ele), bastante comum no uso coloquial, ou ao pronome vós, em desuso no português brasileiro. Como não houve dúvidas por parte da turma, a professora passou a seguinte atividade no quadro.

\section{Quadro 3 - Reprodução do quadro-negro (Parte 2)}

Exercícios sobre pronomes pessoais retos:

1. Complete com pronomes pessoais retos:

a) ___ fugimos de casa.

b) ___ deram risada.

c) ___ fui ao mercado.

d) ___ gostas de cinema?

e) ___ viajaremos hoje.

Mesmo com a explicação da professora de que as lacunas deveriam ser preenchidas pelos pronomes retos, alguns alunos demoraram para compreender. A maior dúvida ficou com relação à letra $d$, pois a flexão do verbo gostar, na $2^{a}$ pessoa do singular, era desconhecida por grande parte da turma, uma vez que, na variante coloquial da região, a flexão da segunda pessoa tende a desaparecer (Tu gosta de cinema?). A professora, no entanto, não fez considerações a respeito dessas possibilidades, apenas corrigiu a atividade, com o que encerrou a aula de Língua Portuguesa. 
Perguntada sobre quais materiais utilizava para organizar o planejamento de suas aulas, Luciana respondeu que se apoiava em mais de um livro didático e complementava com os conceitos e explicações de sites da internet. A visão que a professora apresentou na aula observada corresponde à da professora tradicional, que parte da norma, tal como posta pela gramática normativa, ou, como relaciona, como suas fontes de referência, livros didáticos e sites da internet.

$\mathrm{Na}$ atividade proposta, a partir de frases soltas, descontextualizadas, a professora não utilizou o pronome vós, embora nada tenha dito a respeito na sua explicação. Poderíamos tecer longos comentários sobre a forma que a professora abordou a questão dos pronomes com alunos de $5^{\circ}$ ano, mas enfatizaremos duas questões: o uso da gramática pela gramática, tendo como ponto de partida a definição não contextualizada do que se entende por pronome e o descolamento da questão do conhecimento prévio dos alunos, tanto na apresentação dos pronomes (onde está você/vocês? tão utilizado na linguagem televisiva; por que trazer à cena vós?), quanto na flexão verbal, uma vez que no português falado do sul do país, em sua variedade coloquial, ouve-se, predominantemente, apenas duas flexões verbais: a de primeira e a de terceira pessoa, que passou a ser utilizada para todas as demais ( eu posso; tu/você, ele pode, nós pode, eles/vocês pode).

\subsection{O posicionamento da professora no decorrer da formação}

Antes do início da formação, os professores responderam a um questionário, para que os conhecêssemos melhor e pudéssemos preparar oficinas mais condizentes com as suas realidades. Como resposta à pergunta: O que você entende por ensino de análise linguística? Luciana afirmou que o ensino da análise linguística seria a "Realização de práticas pedagógicas que possibilitem experiências de produção e reflexão sobre a língua.".

No decorrer da oficina sobre análise linguística, a professora Luciana, quando foi convidada a falar sobre como trabalhava com a gramática em suas aulas, em meio a seu relato, revelou incertezas sobre o quê e como ensinar gramática.

\section{Quadro 4 - Transcrição de fala da professora Luciana durante a formação}

Os alunos também exigem esse conteúdo gramatical. E eu fico assim, tá e aí? Eu estou tentando usar o meio termo. Tipo, nem só um nem só outro. Mas eles também nos cobram. Então não sei até que ponto a gente trabalha. Eu também fico em dúvida nisso. Como trabalhar? Porque até então eu tinha aprendido de uma forma. E aí tu chega na sala de aula, e se depara com uma outra 
realidade.

Assim como os demais professores, Luciana demonstrou sua insegurança com relação ao trabalho com a gramática. Apesar de sua resposta no questionário inicial estar condizente com o que se espera de tal ensino, sua fala revela que, na prática de sala de aula, a definição de objetos de ensino e o modo como trabalhá-los ainda se apresentam como desafios.

\subsection{O trabalho com projeto didático de gênero (PDG)}

No decorrer dos Ciclos 4 e 5 da formação, a professora Luciana desenvolveu um PDG sobre o gênero verbete, com a finalidade de dar visibilidade a trabalhos efetuados por seus alunos para a Mostra de Iniciação Científica do município sobre Educação Fiscal. Ao final do trabalho, foi produzido um glossário sobre os temas trabalhados, para ser distribuído na comunidade onde se situa a escola. No modelo didático que elaborou para o gênero verbete, três elementos linguísticos foram destacados: (1) o caráter impessoal do gênero, caracterizado pelo uso da $3^{\text {a }}$ pessoa; (2) a nominalização, como forma de auxiliar na escrita do verbete, em função da estrutura organizada, e (3) paralelismo sintático, elemento que foi trabalhado juntamente com a nominalização, também em função da sua relação com a estrutura do gênero.

O primeiro elemento foi contemplado na terceira oficina - Lendo verbetes de glossários, pois, naquele momento, os alunos já teriam conhecimento acerca da situação de comunicação na qual eles estavam inseridos e, ainda, já teriam lido diversos verbetes de glossário. Os demais foram trabalhados em uma oficina específica, a qual pode ser resumida pelo quadro a seguir

\section{Quadro 5-Resumo da Oficina 5}

\begin{tabular}{|l|l|}
\hline Atividade 1 & $\begin{array}{l}\text { Objetivo: ler e compreender as diferentes estruturas sintáticas que podem compor a escrita } \\
\text { de um verbete. }\end{array}$ \\
\hline Atividade 2 & $\begin{array}{l}\text { Objetivo: reescrever dois verbetes da Atividade 1, com o intuito de estabelecer o } \\
\text { paralelismo sintático e compreender princípios importantes da nominalização. }\end{array}$ \\
\hline Atividade 3 & $\begin{array}{l}\text { Objetivo: realizar análise comparativa entre os verbetes reescritos da Atividade } 2 \text { com os } \\
\text { verbetes produzidos pelos alunos em suas produções iniciais; produzir coletivamente uma } \\
\text { reescrita de algum verbete. }\end{array}$ \\
\hline Atividade 4 & Objetivo: sistematizar as aprendizagens a respeito da nominalização e do paralelismo \\
\hline
\end{tabular}


sintático.

Fonte: elaborado pelas autoras.

A seguir, analisaremos duas das atividades desenvolvidas, para o que nos valemos de descrições de situações didáticas e de transcrições de interações ocorridas.

\section{Em sala de aula, a proposta da professora}

\subsection{A Atividade 1}

Antes de iniciar a Atividade 1, Luciana retoma a estrutura de verbete que já construíra com seus alunos na Oficina 4: Entrada: Palavra ou frase (expressão) que apresenta o significado da entrada com outras palavras + Frase(s) que traz(em) informações relevantes para o verbete. Levando tal estrutura em consideração, ela solicita:

\section{Quadro 6 - Transcrição de fala da professora Luciana em sala de aula}

Aí nós vamos pensar naquela estrutura que a gente olhou semana passada, tá? Lembrem que lá, quando a gente tava falando da palavra ou frase que apresenta um verbete, nos verbetes que a gente viu, iniciamos a frase com um tipo de (.) uma classe de palavras específica, um tipo de palavra específica. Alguém lembra qual era?

Ao se referir à estrutura do verbete, Luciana propõe uma atividade metalinguística oral. Quando decide enfocar a estrutura do gênero, possivelmente por saber que os elementos linguísticos significativos estão ligados a essa organização textual, ela transforma uma pequena retomada de estudos em uma atividade metalinguística alinhada à perspectiva de ensino tradicional de gramática, principalmente porque tal abordagem se apresentou como isolada do trabalho até então realizado, pois teve como foco principal a classificação de palavras, isto é, a busca por saber qual era o "[...] tipo de palavra específica."

Tal atividade foi a maneira que Luciana encontrou para introduzir a nominalização, isto é, ela recorreu à classe morfológica substantivo para iniciar o trabalho planejado. No entanto, essa atividade, que poderia ser rápida, servindo para embasar os estudos sobre nominalização, passou a ser o centro da aula.

No planejamento da professora, a Atividade 1 apresenta a junção das características da atividade linguística e epilinguística (FRANCHI, 1988). A atividade linguística é realizada por meio da leitura dos verbetes, com a finalidade de levar os alunos a perceberem 
diferentes estruturas sintáticas que, por sua vez, não estabelecem um paralelismo sintático, além de não estarem de acordo com a estrutura proposta para a escrita do verbete pela turma. Já quando os comandos presentes nas alíneas a e b são apresentados, percebemos que a atividade se torna epilinguística, à medida que solicita aos alunos a análise de recursos linguísticos presentes no texto, de modo a propor uma reflexão acerca daqueles usos emprego de verbos ou substantivos para iniciar o verbete.

\section{Quadro 7 - Comando da Atividade 1 a que os alunos tiveram acesso}

a) Vimos que, após a entrada, na estrutura que vamos utilizar para a escrita dos verbetes, há uma palavra ou expressão que apresenta o significado da entrada com outras palavras, de um outro modo. No glossário do site Leãozinho, essa parte do verbete sempre aparece da mesma forma? Por exemplo, sempre inicia com "é" ou "são", ou com palavras, como "conjunto" ou "processo"? b) Localize e escreva no caderno as diferentes palavras que você encontrou no glossário. Depois, apresente suas conclusões aos colegas.

Para a Atividade 1, não havia necessidade de usar nomenclaturas gramaticais, uma vez que os comandos das questões se orientavam para uma análise comparativa entre os diferentes verbetes do glossário. Por isso, a atividade continha tanto procedimentos próprios da atividade linguística quando da epilinguística.

Embora a turma já tivesse tido contato com algumas classes de palavras, como mostramos na descrição da aula observada, não é possível afirmar que os alunos sabiam reconhecê-las, tampouco compreender a função exercida por cada uma delas.

\section{Quadro 8 - Transcrição de fala da professora Luciana e de aluno em sala de aula}

\begin{tabular}{|l|l|}
\hline$[\ldots .]$. & \\
Aluna 5 & Sora, é que eu não me lembro o que é substantivo. \\
Luciana & É aquilo que nomeia. \\
{$[\ldots .]$.} & \\
Luciana & Nós vamos relembrar então. [...] \\
\hline
\end{tabular}

Nas gravações, os alunos afirmavam não lembrar mais o que é substantivo; a professora resolve conceituá-lo, resumidamente: "É aquilo que nomeia". A definição dada por Luciana é a que geralmente aparece, por exemplo, nos livros didáticos de Língua 
Portuguesa. Após falar aos alunos que será necessário retomar o que é substantivo, a professora opta por retomar a classificação das palavras presentes no verbete, sem fazer a comparação entre as estruturas, que permitiria sua manipulação pelos alunos. Nesse caso, a identidade tradicional se sobrepôs ao que havia sido planejado como uma tarefa renovada. A entrada apenas pelo terreno metalinguístico, pela abstração da nomenclatura, impediu que os alunos entendessem a comparação planejada, que os permitiria refletir sobre as estruturas em destaque na atividade.

\subsection{A Atividade 4}

Durante a Oficina 5, a professora, por diversas vezes, alterou o curso de sua aula, destinando vários momentos para discutir a nomenclatura gramatical, em detrimento das atividades previstas no planejamento do PDG. Insegura quanto à aprendizagem dos alunos a respeito dos elementos linguísticos estudados, Luciana recorreu à sua mentora para pedir ajuda na proposição de atividades que pudessem retomar princípios importantes dos elementos linguísticos significativos que acabaram não sendo contemplados nas aulas.

Partiu-se, então, para a manipulação dos elementos nominais, para chegar à metalinguagem, como em alguns exemplos que podem ser visualizados abaixo.

\section{Quadro 9 - Comando da Atividade 4 (Parte I) a que os alunos tiveram acesso}

\section{PENSANDO NO VERBETE - PARTE I}

1. Qual é a palavra que define:

a) homem: indivíduo (exemplo)

b) cachorro:

c) banana:

2. Pinte da mesma cor a palavra em destaque e a sua definição:

a) ABACAXI

[ fruta ] [ instrumento ] [ animal ]

b) PROFESSORA

[ sentimento ] [ profissão ] [ parente ]

VOCÊ PERCEBEU OUE TODAS AS SUAS RESPOSTAS FORAM SUBSTANTIVOS?

Isso aconteceu porque os substantivos dão nome às coisas, como você fez nas atividades 1 e 2. 
Vamos conversar um pouco sobre como os substantivos são importantes para a escrita do verbete?

As atividades da Parte I partiam para um trabalho mais intuitivo, em que os alunos deveriam relacionar a palavra com a sua definição, em uma relação de metonímia. Numa atividade epilinguística, já que os alunos, embora lidassem com palavras e não com texto, deveriam operar sobre a própria linguagem, de modo a pensar a respeito em como definir uma palavra, usando seus conhecimentos acerca das formas linguísticas. Já a atividade intitulada Você percebeu que todas as suas respostas foram substantivos? tinha, em sua essência, características da atividade metalinguística, pois contemplava a nomenclatura gramatical, no caso o substantivo, de modo a sistematizar o que até então os alunos tinham feito.

A professora, ao corrigir Parte I, abre para discussão o emprego do substantivo, à medida que faz a correção coletiva:

\section{Quadro 10 - Transcrição de fala da professora Luciana e de alunos em sala de aula}

\begin{tabular}{|l|l|}
\hline Luciana & $\begin{array}{l}\text { Então, o que que a gente teve que fazer ali na primeira atividade, ali no primeiro } \\
\text { exercício da folhinha? }\end{array}$ \\
Aluno 1 & $\begin{array}{l}\text { A gente tinha que definir as palavras. } \\
\text { Luciana }\end{array}$ \\
Aluna 1 & Definir a palavra. O que vocês usaram para definir essas palavras? \\
Luciana & Substantivos. \\
\hline
\end{tabular}

Depois disso, a turma inicia a Parte II. Como os alunos já haviam realizado uma atividade em que deveriam inserir uma definição para cada palavra, a primeira questão da Parte II tinha como objetivo ir além, alinhando os estudos dos elementos linguísticos significativos com a estrutura do verbete. Assim, primeiro, os alunos perceberiam o paralelismo sintático: a definição sempre tem início com um substantivo, não um substantivo qualquer, mas um que defina a entrada. Além disso, a nominalização, antes estudada principalmente em função dos verbetes lidos pelos alunos, que ora iniciam com verbos, principalmente de ligação, ora com artigos, por exemplo, agora poderia ser deixada de lado, já que eles produziriam seus próprios verbetes, tendo em vista a estrutura que 
criamos. A Parte Il foi concluída com a construção coletiva do verbete nota fiscal. Tratou-se de uma atividade prática que poderia ajudar os alunos em suas produções finais.

\section{Quadro 11 - Comando da Atividade 4 (Parte II) a que os alunos tiveram acesso}

\section{PENSANDO NO VERBETE - PARTE II}

1. Complete os verbetes abaixo com suas palavras:

a) amor: sentimento que

b) escola: local onde

c) prova: avaliação que

2. Desafio para a turma: Vamos construir coletivamente um verbete?

Para este desafio, vamos usar a palavra nota fiscal. Antes de escrever, vamos retomar qual é a estrutura do verbete que iremos produzir para o nosso glossário sobre Educação Fiscal.

Por fim, a professora realiza o fechamento das atividades, conforme pode ser acompanhado na interação abaixo:

\section{Quadro 12 - Transcrição de fala da professora Luciana e de alunos em sala de aula}

\begin{tabular}{|c|c|}
\hline Luciana & Onde tem que ter o substantivo \\
\hline $\begin{array}{l}\text { Aluna } 1 \\
{[\ldots]}\end{array}$ & No verbete. \\
\hline Luciana & Onde no verbete? \\
\hline Aluna 2 & Na palavra ou frase. \\
\hline Aluna 3 & Na apresentação. \\
\hline Luciana & Na apresentação. Por que vai ter que ter um substantivo? \\
\hline Aluna 4 & Porque tem que ter uma palavra para... não sei, sora. \\
\hline Luciana & $\begin{array}{l}\text { Que apresente. Uma palavra que apresente a entrada. Que apresente a palavra ou termo } \\
\text { que a gente (.) vai construir o verbete. E esse substantivo que apresenta é uma palavra } \\
\text { que nomeia as entradas, esse termo ou essa palavra. Tá? Então ele vai nos ajudar a iniciar } \\
\text { e a nossa estrutura de verbete ãh::: sugere que a gente inicie com substantivo porque } \\
\text { elementos anteriores como verbos, artigos juntos, ou só verbos, ou só artigos, ãh::: } \\
\text { desnecessários, porque, se a gente for direto no substantivo, e iniciar (.) lembra do } \\
\text { exemplo da carona que eu falei? Carona: é uma condição gratuita. O 'é' é necessário para } \\
\text { entender?= }\end{array}$ \\
\hline
\end{tabular}




\begin{tabular}{|l|l|}
\hline $\begin{array}{l}\text { Aluno } 1 \\
{[\ldots]}\end{array}$ & $=$ Nã::o \\
Luciana & $\begin{array}{l}\text { Não, não é um elemento essencial. Então, pra escrita da nossa apresentação, pra } \\
\text { objetividade da nossa apresentação, do nosso verbete, a gente vai direto no nome, em } \\
\text { algo que nomeie, que defina essa palavra de entrada, essa palavra ou termo, certo? }\end{array}$
\end{tabular}

Diferentemente do que a professora havia feito anteriormente em que ela apenas enfatizava a nomenclatura gramatical, sem expor aos alunos o motivo pelo qual o substantivo ou, ainda, a nominalização eram importantes, podemos perceber que a docente usa a atividade metalinguística conscientemente, em prol da construção do conhecimento gramatical dos alunos.

É importante atentarmos para o fato de que Luciana parte das atividades epilinguísticas realizadas na Parte I e dos entendimentos que a turma vinha construindo de modo sistemático, para chegar a um entendimento a respeito da escrita do gênero verbete, que havia ficado esquecida em vários momentos anteriores.

\section{Considerações finais}

Sabemos que velhas e novas práticas convivem em sala de aula (MENDONÇA, 2006). Luciana, a professora que acompanhamos, é prova disso. Nas aulas que observamos, é possível ver como é forte a identidade de professor tradicional, o apego à metalinguagem, na sua forma mais abstrata, como rótulo que não faz sentido para o aprendiz. Mesmo em atividade relacionada à produção de um determinado gênero textual, planejada com a finalidade de levar à reflexão sobre o uso de dada estrutura e de seu efeito composicional para tal gênero, o apego à metalinguagem aparece. Mas a procura pelo apoio dos pesquisadores-mentores mostra que a professora quer mudar, partir para o que chamamos de um ensino renovado de gramática. Para que isto aconteça, é decisiva a participação em formações continuadas que fortaleçam a mudança, dando voz, espaço e tempo ao professor, de forma a respeitar o embate de identidades que, uma vez instaurado, pode levá-lo ao desenvolvimento profissional.

\section{Referências}


ANTUNES, I. Gramática contextualizada: limpando o "o pó das ideias simples". São Paulo: Parábola Editorial, 2014.

Muito além da gramática: por um ensino de línguas sem pedras no caminho. São Paulo: Parábola Editorial, 2007.

Aula de português: encontro \& interação. 6. ed. São Paulo: Parábola Editorial, 2003.

BARTIKOSKI, F. V. M.; MATIAS, J. "Sempre a minha maior insegurança": a análise linguística como desafio do professor de Língua Portuguesa. No prelo.

BULEA BRONCKART, E. Didactique de la grammaire: une introduction illustrée. Genebra: Université de Genève, 2016.

BRASIL. Ministério da Educação. Base Nacional Comum Curricular. MEC. Brasília, DF, 2017. Disponível em: <http://basenacionalcomum.mec.gov.br/images/BNCC_2odez_site.pdf> Acesso em 28 dez. 2017.

- Ministério da Educação. Secretaria de Educação Fundamental. Parâmetros curriculares nacionais: terceiro e quarto ciclos. Língua Portuguesa. Brasília: MEC/SEF, 1998.

CAMPS, A. Secuencias didácticas para aprender gramática (SDG). In: CAMPS, A.; ZAYAS, F. (Coord.) Secuencias didácticas para aprender gramática. Barcelona: Editorial Graó, 2006. p. 31-37. E-book

FARACO, C. A. Norma culta brasileira: desatando alguns nós. São Paulo: Parábola Editorial, 2008.

FARACO, C. A. Ensinar x Não ensinar gramática: ainda cabe essa questão? Calidoscópio, v. 4, n. 1, São Leopoldo-RS: Unisinos, jan/abr, 2006, p. 15-26.

FRANCHI, Carlos. Criatividade e Gramática. In: São Paulo. Secretaria de Estado da Educação de São Paulo. Coordenadoria de Estudos e Normas Pedagógicas - CENP, 1988.

GERALDI, J. W. Unidades básica do ensino de português. In: GERALDI, J. W. (Org.) O texto na sala de aula. 4 ed. São Paulo: Ática, 2006. E-book. p. 59-79.

GUIMARÃES, A. M. M.; CARNIN, A. Gêneros de texto, escrita e uma proposta de formação continuada para o desenvolvimento profissional docente. In: Nascimento, E.V.; Cristovão, V.L.L.; Lousada, E. (Org.). Gêneros de texto/discurso: novas práticas e desafios. Campinas: Pontes, 2019, v. 1, p. 85-112

GUIMARÃES, A. M. M. O professor de Língua Portuguesa em processo de formação continuada: conjugando reflexão e ação. Calidoscópio, São Leopoldo, vol. 14, n. 1, p. 35-45, jan./abr., 2016. 
GUIMARÃES, A. M. M. Gêneros textuais e ensino de língua materna: entre o caminho e a pedra. Revista Brasileira de Linguística Aplicada, Belo Horizonte, v.10, n. 2, p. 421-438, 2010.

GUIMARÃES, A. M. M. Construindo propostas de didatização de gênero: desafios e possibilidades. Linguagem em (Dis)curso (Impresso), v. 6, p. 4-12, 2006.

HOLMES, J.; MEYERHOFF, M. The community of practice: theories and methodologies in language and gender research. Language in Society 28/2. p. 173-185, 1999.

MENDONÇA, M. R. S. Análise linguística no ensino médio: um novo olhar, um outro objeto. In: BUNZEN, M.; MENDONÇA, C. (Orgs.). Português no ensino médio e formação do professor. São Paulo: Parábola, 2006. p. 199-226

NEVES, M. H. M. Gramática na escola. 2 ed. São Paulo: Contexto, 1991.

POSSENTI, S. Por que (não) ensinar gramática na escola. Campinas, SP: Mercado de Letras, 1996.

\footnotetext{
'Professora Titular do Programa de Pós-Graduação em Linguística Aplicada da Universidade do Vale do Rio dos Sinos (UNISINOS) e Bolsista de Produtividade em Pesquisa do CNPq.

E-mail: anag@unisinos.br

ii Doutoranda no Programa de Pós-Graduação em Linguística Aplicada, na Universidade do Vale do Rio dos Sinos (UNISINOS) e Mestra pelo mesmo Programa. Bolsista CAPES de Doutorado.

E-mail: femachadobart@gmail.com
} 